\title{
Boron carbide particle fabrication by pulsed laser irradiation of boron particle dispersed in organic solvent with various wavelengths
}

\author{
Yoshie Ishikawa ${ }^{1,2}$, and Naoto Koshizaki ${ }^{2 *}$ \\ 1. Department of Advanced Materials Science, Faculty of Engineering, Kagawa University \\ 2217-20 Hayashi-cho, Takamatsu, Kagawa 761-0396, Japan \\ 2. Nanotechnology Research Institute (NRI), National Institute of Advanced Industrial Science and Technology (AIST), \\ AIST Tsukuba Central 5, 1-1-1 Higashi, Tsukuba, Ibaraki 305-8565, Japan \\ Fax: 81-29-861-4879, e-mail: koshizaki.naoto@aist.go.jp
}

\begin{abstract}
$\mathrm{B}_{4} \mathrm{C}$ spherical particles were fabricated by laser irradiation at various wavelengths $(355,532$, and $1064 \mathrm{~nm}$ ) of $\mathrm{B}$ dispersed in organic solvents. Obtained $\mathrm{B}_{4} \mathrm{C}$ yields were 78,90 , and $84 \%$ in ethanol and 68, 82 and $65 \%$ in ethyl acetate by irradiation at 355, 532 and $1064 \mathrm{~nm}$. The highest $\mathrm{B}_{4} \mathrm{C}$ yield was obtained at $532 \mathrm{~nm}$ in each solvent. Important factors for large $\mathrm{B}_{4} \mathrm{C}$ yield were considered to be laser irradiation at long wavelength and large absorbance.
\end{abstract}

Key words: laser processing, boron carbide, nanoparticles

\section{INTRODUCTION}

Boron carbide $\left(\mathrm{B}_{4} \mathrm{C}\right)$ is widely used for abrasive material in polishing and grinding media, and ideal control and shielding media in nuclear industry, due to the extreme hardness and large neutron absorption cross-section of ${ }^{10} \mathrm{~B}$. Especially $\mathrm{B}_{4} \mathrm{C}$ particle is expected for boron neutron capture therapy (BNCT) agent application $[1,2]$. BNCT is based on tumor destruction by $\alpha$ particles produced from nuclear division of ${ }^{10} \mathrm{~B}$ ingested in the tumor cells $[3,4]$. The energy of the released $\alpha$ particle is deposited within $10 \mu \mathrm{m}$ of the site of neutron capture in tissue, resulting in the selective destruction of tumor cells of equivalent size.

Boron carbide can typically be produced by carbothermal reduction of boric acid or boron oxide at temperature above $1000{ }^{\circ} \mathrm{C}[5,6]$. However, obtained products are generally contaminated with carbon compounds. Moreover, these products are ordinarily large grains in micrometer size, and consequently need a further milling process, which possibly contaminates the products from the grinding media, to produce small particles [6]. Chemical vapor deposition (CVD) is also employed for boron carbide particle fabrication, although $\mathrm{BCl}_{3}$ and borane gases with strong toxicity have to be used as a boron source [7]. closo- $\mathrm{C}_{2} \mathrm{~B}_{10} \mathrm{H}_{2}$ (dicarbo-closo-decaborane(12)) is also a raw material for $\mathrm{B}_{4} \mathrm{C}$ fabrication in CVD method [8], although closo$\mathrm{C}_{2} \mathrm{~B}_{10} \mathrm{H}_{2}$ is generally very expensive. Therefore, a simple, harmless, and low-cost technique for the preparation of highly pure $\mathrm{B}_{4} \mathrm{C}$ particles is required.

We have reported $\mathrm{B}_{4} \mathrm{C}$ particle fabrication by laser irradiation of $\mathrm{B}$ powder dispersed in liquid phase under atmospheric pressure and room temperature [9]. The technique of laser irradiation onto dispersed powder or a plate placed in liquid has been attractively investigated to fabricate small particles. Various particles prepared by this technique have already been reported for noble metal and metal oxide [10-13]. This technique has several advantages over conventional nanoparticle preparation in liquid phase $[9,14,15]$; (1) highly pure nanoparticles with less use of surfactant molecules mostly toxic in biological system, (2) crystallized nanoparticle formation due to the transient high-temperature process induced by pulsed laser irradiation, and (3) fabrication of particles that are difficult to be chemically processed in liquid. In this paper, we report the effect of irradiation laser wavelength on the yield of obtained $\mathrm{B}_{4} \mathrm{C}$ particles. Because production yield increase is generally an important challenge in laser materials processing, this study may be helpful for BNCT agent application of $\mathrm{B}_{4} \mathrm{C}$ particle produced by this technique.

\section{EXPERIMENTAL}

Boron powder (99.995\%, Aldrich Chemical Company, Inc.) of $0.24 \mathrm{mg}$ was dispersed in $6 \mathrm{ml}$ organic solvent, ethanol (99.5\%, Wako Pure chemical Industries, Ltd.) or ethyl acetate $(99.5 \%$, Wako Pure chemical Industries, Ltd.), in a glass vessel. The B powder in organic solvent was then irradiated for $180 \mathrm{~min}$ at the wavelength of 355 , 532 , or $1064 \mathrm{~nm}$ from Nd:YAG (yttrium aluminum garnet) laser operated at $10 \mathrm{~Hz}$ with $1.5 \mathrm{~J} \mathrm{~cm}^{-2}$ with a pulse width of $7 \mathrm{~ns}$. The laser beam was focused $2 \mathrm{~mm}$ below the suspension surface using a lens with the focal length of $50 \mathrm{~mm}$. The suspension was agitated using a magnetic stirrer during irradiation. The particles obtained by laser irradiation of $\mathrm{B}$ in organic solvent were treated with $\mathrm{HNO}_{3}$ by the following procedures to remove unreacted raw $\mathrm{B}$ and by-product $\mathrm{H}_{3} \mathrm{BO}_{3}$. First, organic solvent was completely evaporated using a centrifugal evaporator and the obtained particles were dispersed in $6.2 \mathrm{M} \mathrm{HNO}_{3}$ for $24 \mathrm{~h}$. Next, B and $\mathrm{H}_{3} \mathrm{BO}_{3}$ were completely dissolved in $\mathrm{HNO}_{3}$, whereas $\mathrm{B}_{4} \mathrm{C}$ particles remained undissolved. After the dissolution process, $\mathrm{B}_{4} \mathrm{C}$ particles were separated from the supernatant by centrifugation. The $\mathrm{B}$ concentration of the supernatant was then analyzed by inductively coupled plasma optical emission spectrometry 
(ICP-OES) measurement for $\mathrm{B}_{4} \mathrm{C}$ yield evaluation. At the same time, collected $\mathrm{B}_{4} \mathrm{C}$ particles were repeatedly rinsed with de-ionized water by centrifugation to remove $\mathrm{HNO}_{3}$. The as-prepared suspension and suspension after the $\mathrm{HNO}_{3}$ treatment were dropped onto Si substrate and dried in air for x-ray powder diffraction analysis (XRD) (Rigaku RAD-C system) with $\mathrm{Cu} K \alpha$ radiation. Morphology observation of the particles was performed by a field emission scanning electron microscope (SEM) (Hitachi S4800). The particles treated with $\mathrm{HNO}_{3}$ were also mounted onto a carbon-coated grid for transmission electron microscope (TEM) (JEOL JEM 2010) observation.

Absorbance of B powder dispersed in organic solvent was evaluated by measuring optical transmittance spectra of sufficiently diluted suspension $\left(7.9 \times 10^{-4} \mathrm{M}\right)$ to suppress multiple scattering effect.

\section{RESULTS AND DISCUSSION}

Raw B particles and particles obtained by laser irradiation in ethanol at various wavelengths and subsequent $\mathrm{HNO}_{3}$ treatment to eliminate by-product were observed by SEM measurement (Fig. 1). Connected irregular grains 50 to $100 \mathrm{~nm}$ in size were observed in particles before irradiation (Fig. 1(a)). In contrast, spherical particles 50 to $400 \mathrm{~nm}$ in diameter were formed by laser irradiation at all wavelengths we examined (Figs. 1(b)-(d)). Similar spherical particles were also obtained by laser irradiation at all wavelengths in ethyl acetate. The spherical morphology of the particles suggested that the raw B grains were melted by laser heating. Absorbed photon energy $E_{a b s}\left(\mathrm{~J} \mathrm{~mol}^{-1}\right.$ pulse $\left.^{-1}\right)$ of irradiated particles in the region between the suspension surface and $1 \mu \mathrm{m}$ below the surface was calculated by the equation [16],

$$
E_{a b s}=\frac{I\left(1-10^{-A}\right)}{C_{B} l_{0}}
$$

where $I, A, C_{B}$, and $l_{0}$ are the laser fluence $\left(1.5 \mathrm{~J} \mathrm{~cm}^{-2}\right.$ pulse $\left.{ }^{-1}\right)$, absorbance at each wavelength, atomic mole number of B per unit volume in suspension $\left(3.7 \times 10^{-6}\right.$ mol $\left.\mathrm{cm}^{-3}\right)$, and the optical path $\left(1 \times 10^{-4} \mathrm{~cm}\right)$. The absorbance $A$ in the suspension with $1 \mu \mathrm{m}$ optical path length was estimated by the Lambert-Beer equation using the absorbance measured from diluted suspension, and listed in Table I. $E_{a b s}$ at each wavelength in a solvent was also evaluated and demonstrated in Table I. Since the required energy for B fusion was calculated as $4.5 \times$ $10^{5} \mathrm{~J} \mathrm{~mol}^{-1}$ based on the method in Ref. 16, the estimated $E_{a b s}$ in any wavelength and solvent were sufficient to melt the B particles by laser irradiation.

The XRD patterns of B particles before and after laser

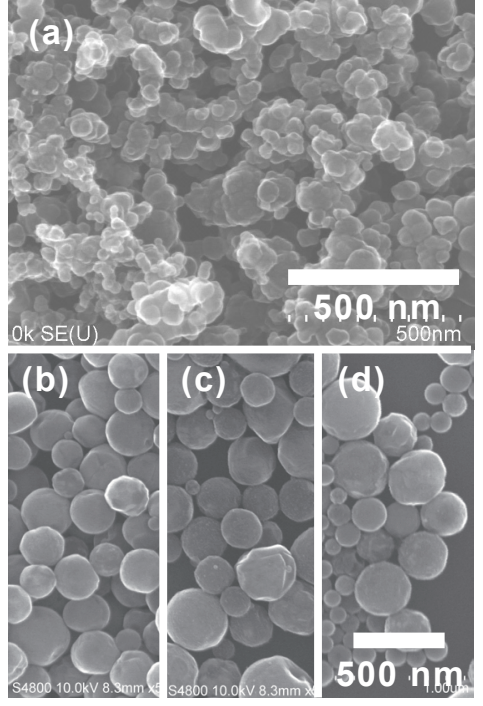

Fig. 1 SEM images of particles before and after laser irradiation in ethanol. (a) B particles before laser irradiation. Particles irradiated with (b) 355 $\mathrm{nm}$, (c) $532 \mathrm{~nm}$, and (d) $1064 \mathrm{~nm}$, and subsequent $\mathrm{HNO}_{3}$ treatment.

irradiation with $532 \mathrm{~nm}$ in ethyl acetate without subsequent $\mathrm{HNO}_{3}$ treatment are presented in Fig. 2 . Boron particles before laser irradiation were amorphous (Fig. 2(a)). In contrast, $\mathrm{B}_{4} \mathrm{C}$ peaks and marginal $\mathrm{H}_{3} \mathrm{BO}_{3}$ peak were observed in particles obtained after laser irradiation with $532 \mathrm{~nm}$ in ethyl acetate (Fig. 2(b)), indicating that $\mathrm{B}_{4} \mathrm{C}$ crystals and slight $\mathrm{H}_{3} \mathrm{BO}_{3}$ were formed by laser irradiation. The $\mathrm{B}_{4} \mathrm{C}$ peaks were also observed in particles even after the $\mathrm{HNO}_{3}$ treatment. Similar results were obtained by irradiation with any

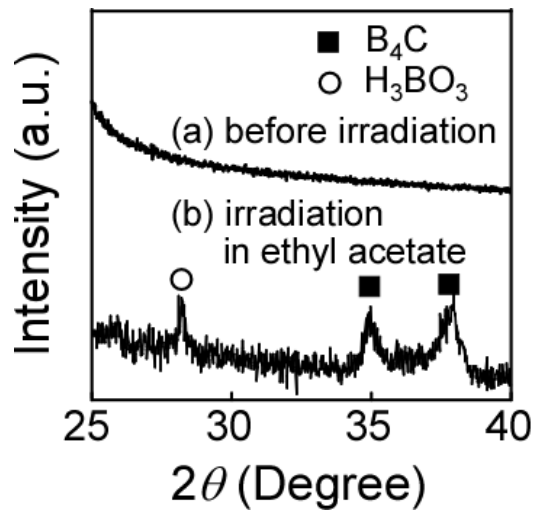

Fig. $2 \mathrm{X}$-ray powder diffraction spectra of particles (a) before and (b) after laser irradiation with $532 \mathrm{~nm}$ in ethyl acetate.

Table I. Measured absorbance, estimated $A$ and $E_{a b s}$, and $\mathrm{B}_{4} \mathrm{C}$ yield.

\begin{tabular}{|c|c|c|c|c|c|c|}
\hline & \multicolumn{2}{|c|}{$355 \mathrm{~nm}$} & \multicolumn{2}{|c|}{$532 \mathrm{~nm}$} & \multicolumn{2}{|c|}{$1064 \mathrm{~nm}$} \\
\hline & Ethanol & Ethyl acetate & Ethanol & Ethyl acetate & Ethanol & Ethyl acetate \\
\hline Measured absorbance & 0.50 & 0.32 & 0.47 & 0.32 & 0.17 & 0.15 \\
\hline Estimated $A$ & $2.3 \times 10^{-4}$ & $1.5 \times 10^{-4}$ & $2.2 \times 10^{-4}$ & $1.5 \times 10^{-4}$ & $8.0 \times 10^{-5}$ & $7.1 \times 10^{-5}$ \\
\hline$E_{a b s}\left(\mathrm{~J} \mathrm{~mol}^{-1}\right.$ pulse $\left.^{-1}\right)$ & $2.2 \times 10^{6}$ & $1.4 \times 10^{6}$ & $2.0 \times 10^{6}$ & $1.4 \times 10^{6}$ & $7.4 \times 10^{5}$ & $6.6 \times 10^{5}$ \\
\hline $\mathrm{B}_{4} \mathrm{C}$ yield $(\%)$ & 78 & 68 & 90 & 82 & 84 & 65 \\
\hline
\end{tabular}


wavelength and in both solvents. $\mathrm{B}_{4} \mathrm{C}$ formation process was considered to proceed as follows. The $\mathrm{B}$ particles irradiated with laser absorbed photon energy, and formed $\mathrm{B}$ droplets by melting. Atomic $\mathrm{C}$ was formed from thermal decomposition of solvent molecules (ethanol or ethyl acetate) surrounding melted B with extremely high temperature or direct breakdown of these solvent molecule by laser energy. This atomic $\mathrm{C}$ probably dissolved into melted $\mathrm{B}$, and finally $\mathrm{B}_{4} \mathrm{C}$ formed after cooling.

$\mathrm{B}_{4} \mathrm{C}$ yields obtained at each wavelength in solvent were displayed in Table 1. The highest yields were obtained by irradiation at $532 \mathrm{~nm}$ in both solvents. Surprisingly $\mathrm{B}_{4} \mathrm{C}$ yields at $1064 \mathrm{~nm}$ were comparable to or over those at $355 \mathrm{~nm}$ even with low absorbance at $1064 \mathrm{~nm}$. Figure 3 shows relationship between $\mathrm{B}_{4} \mathrm{C}$ yield divided by absorbance and laser wavelength. The $\mathrm{B}_{4} \mathrm{C}$ yield per absorbance increased with irradiation laser wavelength.

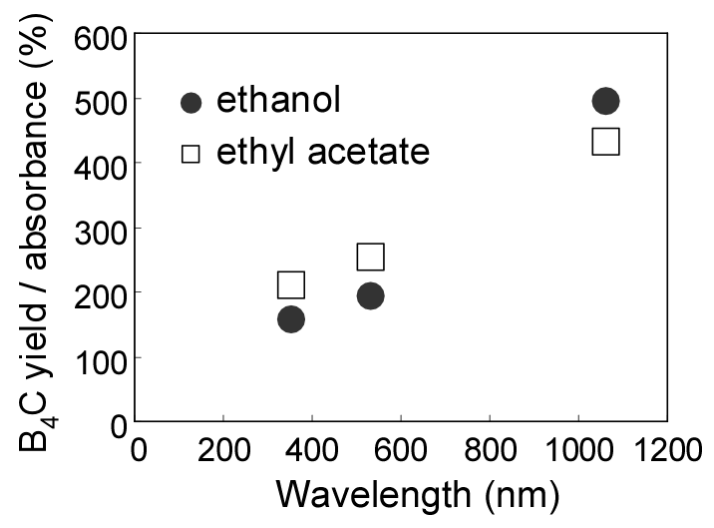

Fig. 3 Relationship between $\mathrm{B}_{4} \mathrm{C}$ yield divided by absorbance and laser wavelength.

This result suggests that irradiation of laser light with longer wavelength is advantageous to $\mathrm{B}_{4} \mathrm{C}$ production when optical absorption energy is the same in the wavelength range we tested. However, larger $\mathrm{B}_{4} \mathrm{C}$ yield at $532 \mathrm{~nm}$ than that at $1064 \mathrm{~nm}$ was mainly due to the large absorbance at $532 \mathrm{~nm}$. Therefore, we might be able to find optimal laser wavelength by using laser with different wavelength for large $\mathrm{B}_{4} \mathrm{C}$ yield. However, further investigation is necessary to approach the large $\mathrm{B}_{4} \mathrm{C}$ yield.

\section{CONCLUSION}

In conclusion, spherical $\mathrm{B}_{4} \mathrm{C}$ particles were obtained by laser irradiation at various wavelengths $(355,532$, or $1064 \mathrm{~nm}$ ) of B dispersed in ethanol or ethyl acetate. Both the laser irradiation at long wavelength and the large absorbance were important for quantity synthesis of the $\mathrm{B}_{4} \mathrm{C}$ particle. The highest $\mathrm{B}_{4} \mathrm{C}$ yields $(90$ and $82 \%$ in ethanol and ethyl acetate) were obtained by laser irradiation at $532 \mathrm{~nm}$ in experimented wavelengths.

\section{ACKNOWLEDGMENTS}

The present work was supported by the Research for Promoting Technology Seeds of Japan Science and
Technology Agency and the Grant-in-Aid for Young Scientists (Start-up) of the Japan Society for the promotion of Science. A part of this study was financially supported by the Budget for Nuclear Research or the Ministry of Education, Culture, Sports, Science and Technology, based on the screening and counseling by the Atomic Energy Commission and the Grant-in-Aid for Scientific Research (B) of the Japan Society for the Promotion of Science.

\section{REFERENCES}

[1] M. W. Mortensen, P. G. Sorensen, O. Bjorkdahl, M. R. Jensen, H. J. G. Gundersen, and T. Bjornholm, Applied Radiation and Isotopes, 64, 315-24 (2006).

[2] M. W. Mortensen, O. Bjorkdahl, P. G. Sorensen, T. Hansen, M. R. Jensen, H. J. G. Gundersen, and T. Bjornholm, Bioconjugate Chemistry, 17, 284-90 (2006).

[3] R. F. Barth, A. H. Soloway, and R. G. Fairchild, Cancer Research, 50, 1061-70 (1990).

[4] M. F. Hawthorne, R. J. Wiersema, and M. Takasugi, Journal of Medicinal Chemistry, 15, 449-52 (1972).

[5] C. H. Jung, M. J. Lee, and C. J. Kim, Materials Letters, 58, 609-14 (2004).

[6] A. Sinha, T. Mahata, and B. P. Sharma, Journal of Nuclear Materials, 301, 165-69 (2002).

[7] K. E. Lee, C. O. Kim, M. J. Park, and J. H. Kim, 9th European Conference on Organised Films (ECOF2004), 1637-40 (2004).

[8] A. O. Sezer and J. I. Brand, Materials Science and Engineering B: Solid-State Materials for Advanced Technology, 79, 191-202 (2001).

[9] Y. Ishikawa, Y. Shimizu, T. Sasaki, and N. Koshizaki, Applied Physics Letters, 91, 161110-1-3 (2007).

[10] A. Henglein, Journal of Physical Chemistry, 97, 5457-71 (1993).

[11] J. Neddersen, G. Chumanov, and T. M. Cotton, Applied Spectroscopy, 47, 1959-64 (1993).

[12] F. Mafuné, J. Kohno, Y. Takeda, T. Kondow, and H. Sawabe, Journal of Physical Chemistry B, 104, 8333-37 (2000).

[13] C. H. Liang, Y. Shimizu, M. Masuda, T. Sasaki, and N. Koshizaki, Chemistry of Materials, 16, 963-65 (2004).

[14] A. V. Simakin, V. V. Voronov, G. A. Shafeev, R. Brayner, and F. Bozon-Verduraz, Chemical Physics Letters, 348, 182-86 (2001).

[15] Y. Ishikawa, Y. Shimizu, T. Sasaki, and N. Koshizaki, Journal of Colloid and Interface Science, 300, 612-15 (2006).

[16] S. Inasawa, M. Sugiyama, and Y. Yamaguchi, Journal of Physical Chemistry B, 109, 9404-10 (2005).

(Received December 22, 2008; Accepted April 3, 2009) 